\title{
Analysis of starting resistance moment of direct drive wind turbine
}

\author{
Bin He, Quan Liu
}

Mechanical and Electrical Engineering School, Beijing Information Science \& Technology University, Beijing, 100192, China

\begin{abstract}
Permanent magnet motor in the process of running, the permanent magnets provided the magnetic field, the core will have a strong attraction, produce the cogging torque and torque ripple, vibration and noise and other disharmony factors, seriously affect the control precision of the motor system.Therefore, in the design of permanent magnet wind turbine generator, weaken the cogging torque is very important.
\end{abstract}

Keywords: Permanent magnet motor,control precision,cogging torque

\section{Preface}

Wind energy is a kind of renewable energy,and it is also one of the most abund antenergy for human development and utilization.There are various ways people use wind energy, and modern society is the main way of using wind power, the wind energy is converted into easy to transport and control of power to use.Traditional doubly-fed induction generator excitation system is complex, with frequent gear transmission failure, maintenance difficulties, greatly limits the development of wind turbine applications.

The direct-drive permanent magnet wind turbine is not only remove the gear box that is easy to be damaged, also use permanent magnets to replace electric excitation, greatly improve the reliability of the system operation, efficiency is also increased.Direct-drive permanent magnet wind turbine, however, there are some technical problems need to solve.The permanent magnet make permanent magnet generator produce the cogging torque, the motor starting performance and running stability of the proposed the new challenge, as far as possible the extinction of the cogging torque, become a direct-drive major research topic of permanent magnet wind turbine .

1 The cogging torque generating mechanism and analysis method

\subsection{The reason of cogging torque}

The cogging torque is the inherent 
characteristics of permanent magnet motor, especially for low speed wind power generator, the cogging torque is too large, will cause strong vibration and noise.The permanent magnet is relative to the armature winding, both the outer and the inner rotor. The armature winding in the open core with a notch, regardless of whether or not with current, will produce a magnetic force.

Once the rotor starts to rotate, the magnetic force on the formation of torque, to maintain the original state, which is the physical embodiment of cogging torque.In the process of rotation of the rotor, permanent magnet track to the region week changes greatly, which led to the magnetic field energy changes, expand the influence of cogging torque.

\section{2the cogging torque analysis method}

\section{Finite element analysis method}

Finite element method in electromagnetic calculation, have used the very mature, the development of commercial software such as Ansys, Ansoft has high accuracy.With finite element method can get the magnetic field distribution, the torque by the node to take.It is concluded that magnetic volume and surface force as:

$$
\begin{gathered}
f_{i}^{\Omega}=\partial_{k} T_{i k} \\
f_{i}^{\Gamma}=\int_{1}^{2} T_{i k} n_{k} d \alpha
\end{gathered}
$$

The magnetic fields of the Maxwell's tension:

$$
T_{i k}=H_{i} B_{k}-\delta_{i k} \int_{0}^{H} B d H
$$

The virtual displacement work as:

$$
\delta W=-\int T_{i k} \partial_{k} N_{n} d v
$$

Virtual displacement node shape functions:

$$
\delta 1_{i}=\sum_{n} N_{n} \delta 1_{n i}
$$

For the NTH node forces:

$$
f_{n i}=-\int_{\Omega} T_{i k} \partial_{k} N_{n} d v
$$

The effect of each node and, get the whole volume on the torque:

$$
\bar{T}=\sum_{l \in V} \bar{r}_{l} \times \bar{f}_{l}
$$

\section{The effective methods to reduce the cogging torque}

With the constant improvement of the permanent magnet material performance, remanent magnetism of magnetic steel is also attractive to alveolar, the greater the interaction between permanent magnet and slotted core, produce bigger the cogging torque. When the rotating permanent magnet direct-drive generator, produce torque ripple, vibration and noise, they will directly affect the permanent magnet direct drive wind turbine running stability and low speed startup performance.

In the design requirements through winding magnetic flux is changing, all $d \Phi / d t$ everywhere is not zero.But the magnetic flux of the total rate of change is very small, is the best way to pole magnetic flux is invariable, the cogging torque are as small as possible.To this end, we use the following methods to weaken the cogging torque.

\subsection{Slit width}

Under the condition of wire to make notch become smaller, the tooth and the magnetic flux become as small as possible, if necessary, can use magnetic slot wedge.

As shown in figure 1, the cogging torque amplitude increases with the slit width b0 to decrease then increase, b0 size should choose between $9 \mathrm{~mm}$ to $15 \mathrm{~mm}$, this size range the cogging torque ripple minimum.B0, the greater the slot wedge in the assembly, the more difficult, therefore integrated magnetic properties and assembly technology, will be the best value is b0 slit width $=10 \mathrm{~mm}$. 


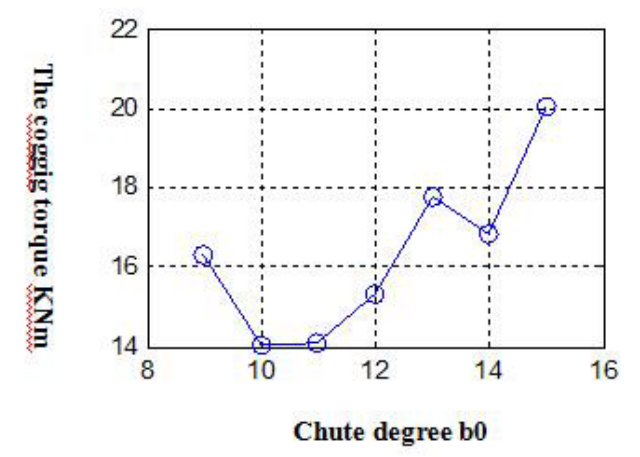

Figure 1.Different slit width the cogging torque curve peak change

\subsection{Chute}

USES the oblique groove and obliquepole can effectively reduce thecogging torque, but it's hard to largepermanent magnet direct-drive generator adopts chute, craft is not easy toachieve, and using inclined extremelyeasily, but the magnetic material is used up big, the price is higher.

Motor stator chute design is a common way to weaken the torque ripple, and after the chute motor as inaxial direction can be divided into multiple layers, each layer can be treated as a unit of motor, the cogging torque of each layer unit motor phasedue to the chute, added togetherto weaken the cogging torque peaks.

Because of the chute Angle is small, generally $0 \sim 5^{\circ}$, the cogging torque waveform trend does not produce big changes.Figure $2 \sim 3$ for CAE calculation results, the cogging torque cycle after the chute and waveform trend is almost the same, less peak.Zero cogging torque ripple when the value of $21.073 \mathrm{kNm}$, chute after 0.42 degrees torque ripple value stable in $6.637 \mathrm{kNm}$, width decrease fluctuation is bigger.The size of the wind turbine is bigger, this example USES the outer rotor of the generator stator outer diameter is $4310 \mathrm{~mm}$, chute to weaken the torque ripple effect is obvious.

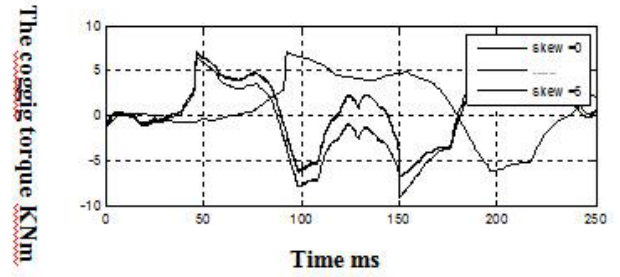

Figure 2.Different chute degree the cogging torque waveform

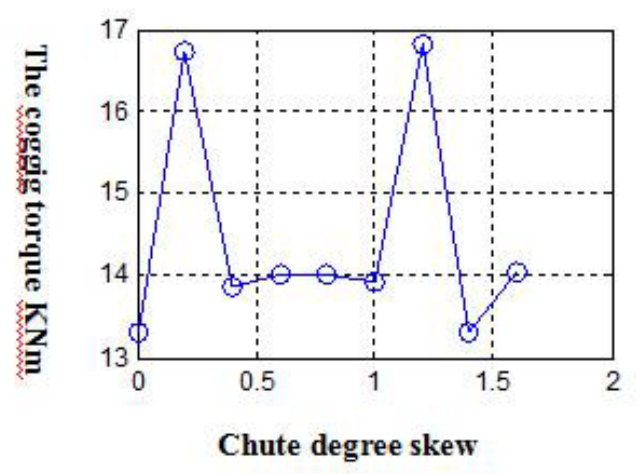

Figure 3.Different chute peak curve degree the cogging torque

\subsection{Arc coefficient}

Magnetic circuit and magnetic flux itself has asked for arc coefficient, surface generally installed magnets, arc coefficient is not less than 0.8.According to the actual notches, choose a tooth, corresponding change the minimum magnetic flux in the process of spinning area, can be determined using arc number should be greater than 0.8 , even if the arc is no effect on the output coefficient is 1 .

Arc coefficient is permanent magnets are arranged density parameters, evaluation for table structure, the $\mathrm{N}$ S pole permanent magnet arranged alternately, approximate sine is formed in the air gap flux density distribution, the technological gap between adjacent permanent magnets, adjust the gap to make magnetic induction line uniform distribution as far as possible to achieve uniform magnetic field.Permanent magnet synchronous motor rotate a fundamental wave of the cogging torque cycles and the greatest common divisor of the stator slot number and the number of the rotor 


$$
\gamma=\frac{N_{P} N_{S}}{N_{G}}=N_{L}
$$

According to Z.Q.Z hu, the number of the best coefficient formula:

$$
\alpha_{p}=\frac{N-1}{N}+k_{2}
$$

As can be seen from the figure 4, the cogging torque ripple decrease then increase first, within the range of $0.928 \sim 0.938$.Considering the conducting bar permanent magnet installation to do process, will the distance between permanet magnet roundness, $1 \mathrm{~mm}$, the arc coefficient of 0.932 .

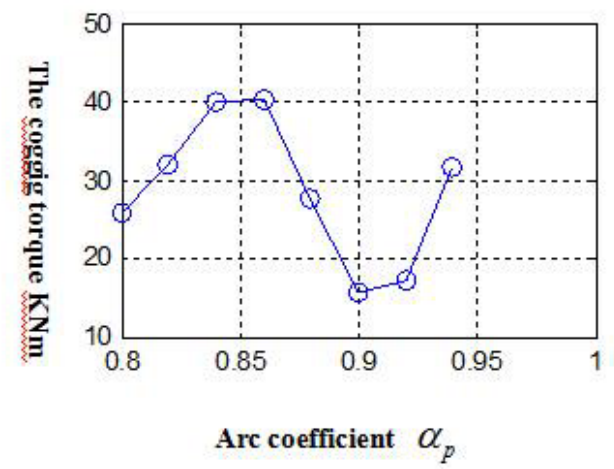

Figure 4.Different arc coefficient of the cogging torque curve peak change

\subsection{The optimum parameters of the motor}

According to the previous analysis, get 84 pole 84 slot motor cogging torque minimum the best parameter combination of specific parameters are shown in table 1 , the rabbet width, arc coefficient,chute degree are adjusted.The cogging torque waveform comparison before and after optimization are shown, the trend of the two curves, cycle, have no obvious change, volatility is slightly different.This is due to the optimization of the parameters are not fundamentally change the motor groove structure, permanent magnet to the nonlinear attract laws of stator core did not change obviously.
Table 1.84 pole 84 slot motor cogging torque characteristics of optimal parameters

\begin{tabular}{|l|c|c|}
\hline $\begin{array}{l}\text { To optimize the } \\
\text { project }\end{array}$ & $\begin{array}{l}\text { The optimized } \\
\text { parameters }\end{array}$ & $\begin{array}{l}\text { Before optimization } \\
\text { parameters }\end{array}$ \\
\hline The number/slot number & 84 pole288 & 84 pole288 \\
\hline Slot opening width(mm) & 10 & 14 \\
\hline Arc coefficient & 0.9 & 0.9 \\
\hline Chute degree & 0 & 3 \\
\hline
\end{tabular}

Can be seen from the figure 5 the cogging torque fluctuation decreased from 12.252 to $6.637 \mathrm{KNm}$, reduced $47 \%$; The motor structure design parameters of fine-tuning have played an important role in to weaken the cogging torque, effect is obvious.

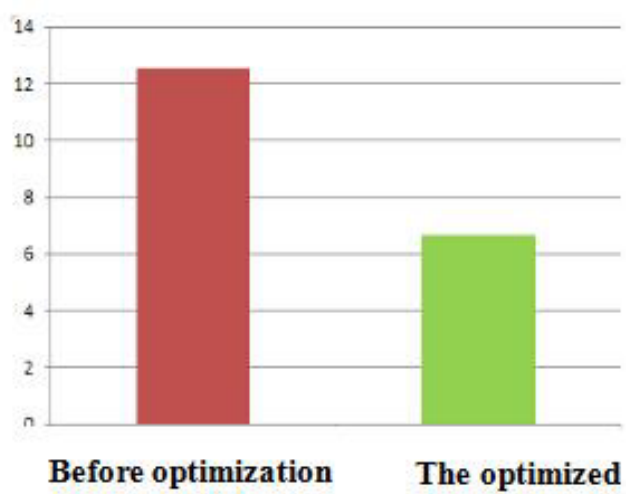

Figure 5.Peak torque contrast before and after optimization

To sum up, the local structure by adjusting the motor parameters can be found outside the wind turbine rotor cogging torque ripple minimum parameters combination, fundamentally change the motor cogging structure and size, eliminate or greatly weakened the cogging torque, so by fine-tuning the motor structure parameters is of great significance to the design of the wind turbine, improve the external rotor torque performance of wind turbines.

\section{Brief summary}

Starting torque of permanent magnet direct-drive generator are analyzed, and the mechanism of the cogging torque is studied.Puts forward some methods to weaken the cogging 
torque, chute, slit width and the coefficient of arc generator in the aspects of optimized design, the optimum parameters of $2 \mathrm{MW}$ wind turbine is obtained, and the design of this type of permanent magnet generator has played a reference.

\section{References}

1. Santiago Arnaltes, Juan Carlos Burgos. Control of Permanent-Magnet Generators Applied to Variable- Speed Wind-Energy Systems Connected to the Grid Chinchilla. IEEE Transaction on Energy Conversion, 2006,21(1): 130-135

2. Pinghua Tang, Guijie Yang, Min Luo, etal. A Current Control Scheme with Tracking Mode for PMSM System. 1st International Symposium on Systems and Control in Aerospace and Astronautics, Harbin,2006,872-876

3. R.K.Sharma,V.Sanadhya, L.Behera, etal. Vector control of a permanent magnet synchronous motor. INDICON 2008, Kanpur,India, 2008,81-86

4. Kelvin Tan,Syed Islam. Optimum control strategies in energy conversion of PMSG wind turbine system without mechanical sensors. IEEE Transactions On Energy Conversion, 2004,19(2): 392-399

5. Monica Chinchilla, Santiago Arnaltes, Juan Carlos Burgos. Control of permanent-magnet generators applied to variable-speed wind-energy systems connected to the grid. IEEE Transactions on Energy

Conversion,2006,21(3) 